\title{
Multiple genetic control of acetate-induced olfactory responses in Drosophila melanogaster larvae
}

\author{
MATTHEW COBB* AND FRÉDÉRIC DANNET \\ Mécanismes de Communication, NAM URA-CNRS 1491, Bât 446, Université Paris Sud, 91405 Orsay, France
}

\begin{abstract}
Behavioural responses of Drosophila melanogaster larvae were measured in response to olfactory stimulation with an homologous series of eight aliphatic $n$-acetates (methyl ...octyl actetate) and with cis-vaccenyl acetate. Larvae tended to be attracted to short-chain acetates (methyl...pentyl) and repelled by longer chain acetates (hexyl, heptyl and octyl acetate). All larvae were strongly attracted to propyl acetate, irrespective of the dose studied. Larval olfactory responses generally declined with age. Two geographical strains showed specific anosmias. Katsunuma (Japan) larvae showed no response to hexyl acetate; chromosome substitution showed this behaviour to be controlled by genes on chromosome II. Tai (Ivory Coast) larvae showed no response to pentyl acetate; chromosome substitution showed that two genetic factors were primarily involved, on the $\mathrm{X}$ chromosome and chromosome III. The response was modulated by chromosome II. No effect of the Y chromosome was found. Two olfactory mutants were studied, olfC (X chromosome) and Indf (chromosome III); both mutants showed abnormal responses to certain acetates. The results are discussed in terms of various models of olfactory processing and the implications of these models for the number of genes involved in olfaction.
\end{abstract}

Keywords: acetates, Drosophila melanogaster, larvae, olfaction.

\section{Introduction}

How many receptors are involved in sensing the wide range of odours which most organisms can distinguish? This is one of the fundamental questions in the study of olfaction and is of particular interest to geneticists because it may have major consequences for our understanding of genome structure. One possibility is that each odour is detected by a unique receptor, which in turn is the product of a unique gene. Given the number of odours which the human nose can detect, this would imply that around 10000 of our genes - at least 10 per cent of the human genome - are involved in olfaction. Support for this hypothesis - or at least for the involvement of a very large number of genes in olfaction - has come from Buck \& Axel (1991) who cloned and characterized in rats several dozen members of a multigene family of proteins, apparently transmembrane receptors, the expression of which was limited to olfactory epithelium. One of these proteins has been shown to act as an olfactory receptor when expressed in Xenopus eggs (Raming et al., 1993), and

\footnotetext{
${ }^{*}$ Correspondence
}

the rat sequences have been used to find similar expression patterns in the cat-fish (Ngai et al., 1993).

On the other hand, models of olfactory processing are frequently based upon integrative functions, whereby a relatively small number of receptors detecting key chemicophysical features or 'odour primitives' (chemical function, chain length, the presence of double-bonds or rings, etc.) interact in the olfactory pathway according to strict computational rules, via glomeruli and other structures, to give a 'collective molecular image' which presumably corresponds to odour sensation (e.g. Shepherd, 1991; Mori et al., 1992). This approach often leans heavily on computational models of visual processing where, obviously, there cannot be a genetically coded receptor for each detectable object. The two hypotheses are not necessarily contradictory; a 'soft' version combining elements of both would imply the presence of a large number of separately coded 'odour primitive' receptors which are integrated in a genetically coded computational system capable of distinguishing complex odours.

One of the difficulties in finding decisive evidence to support these various hypotheses is the need to use a biological system which combines neuronal and 
sensory simplicity with genetic manipulability; Drosophila melanogaster, and in particular the larva of this species, constitute an appropriate subject for study.

The relative facility with which mutants can be created and the existence of many wild-type strains, allow for the detection of genetic variants which can both reveal the number of genes involved in the olfactory phenotype and give some clues as to their function. A number of $D$. melanogaster variants showing altered larval olfactory responses have been isolated, mostly through mutagenesis (Rodrigues, 1980; Monte et al., 1989; Lilly \& Carlson, 1989; Ayyub et al., 1990; Cobb et al., 1992). However, many of these variants have pleiotropic effects on nonolfactory systems, suggesting that the genes affected are not specific to olfaction, and therefore probably do not code for receptors either for unique odours or for 'odour primitives' (for reviews, see Carlson, 1991; Cobb et al., 1993).

Larvae have a great advantage over adults because the presumed site of larval olfaction, a dome-like structure known as the dorsal organ, is extremely simple, being innervated by only 21 neurons (Singh \& Singh, 1984; for a review, see Stocker, 1994). This system is entirely independent of the adult olfactory pathway, all the structures involved in larval olfaction being hystolized during pupation. There are no known major integrative organs such as glomeruli in the larva, suggesting that the larval olfactory repertoire must be relatively limited and that the computation of any 'collective molecular image' must involve simple rules and structures. For this reason it should be possible to estimate the total number of odours the system can detect and the number of genes involved. It is possible that different genes are involved in olfaction during the two stages of the insect's life. The far greater number of neurons which innervate each adult antenna $(\sim 1200)$ and the presence of glomeruli in the adult brain suggest that there may be substantial differences in the number and quality of odours detected during the two developmental phases.

Although larval olfactory responses can be easily measured, relatively few odour stimuli have been studied, generally being limited to one or two representatives of a given chemical function (e.g. acetates, alcohols and aldehydes). Whilst this approach has permitted the detection of a range of olfactory mutants, it cannot resolve the fundamental problem of the number of genes involved in olfaction for the simple reason that it does not involve a full cartography of the larval olfactory response.

In a previous study, we investigated larval responses to a homologous series of 10 primary alcohols and found that these odours induced qualitatively and quantitatively different responses, suggesting the presence of more than one class of alcohol receptor in D. melanogaster larvae (Cobb et al., 1992). The possibility that there may be a series of alcohol receptors was supported by our discovery of two specific and total anosmias, one for heptanol (principally on the second chromosome, revealed by chromosome substitution between two geographical strains), the other for nonanol (the Indifferent (Indf) mutants, revealed by EMS mutagenesis of the third chromosome).

Aliphatic acetates constitute an important component of fruit odours (e.g. Berger, 1990); genetic control of responses to these stimuli in Drosophila could be expected to be both rich and varied. Since the beginning of the century, ethyl acetate has been known to attract adult Drosophila (Barrows, 1907) and is normally used in tests of larval olfaction. Siddiqi (1983) found that different regions of the adult antenna responded to different acetates, suggesting the presence of at least two acetate receptors. Responses to other esters have generally not been studied in larvae, apart from iso-pentyl acetate (this substance differs from $n$-pentyl acetate both by chain length and by the fact that the chain is branched, not linear). Reduced responses to either or both ethyl and iso-pentyl acetate in adults and in larvae have been found in strains carrying various olf mutations (Siddiqi, 1983, 1987; Monte et al., 1989; Ayyub et al., 1990) and in adults, ota mutants (Woodard et al., 1989), all of which are on the $\mathrm{X}$ chromosome. olfC mutant adults show a reduced electrophysiological response to butyl acetate (Venard \& Pichon, 1984). Finally, less specific genetic variation for adult responses to ethyl acetate has been found on the second chromosome amongst a Japanese population of flies (Fuyama, 1978) and between populations (Alcorta \& Rubio, 1988). Taken together, these studies suggest that at least four genes on the $\mathrm{X}$ chromosome and at least one on chromosome II are involved in detecting esters, with different genes being associated with different acetates.

cis-Vaccenyl acetate (C18) occurs in adult male $D$. melanogaster and is transferred from males to females during mating. It is thought to inhibit male courtship of a fertilized female and is subsequently introduced into food medium during egg-laying, where it catalyses the attractive effects of food for adult flies (Jallon, 1984; Bartelt et al., 1985; for a review see Ferveur et al., 1989). It may also play a pheromonal role in larvae.

In order to enrich our estimation of the number of genes involved in Drosophila larval olfaction, we investigated the role of four chromosomes (X, Y, II and III) and of four olfactory mutant strains on the responses of $D$. melanogaster larvae to a homologous series of eight aliphatic $n$-acetates and to cis-vaccenyl acetate. 


\section{Materials and methods}

\section{(a) Drosophila melanogaster strains}

Canton-S: A laboratory strain originally from the U.S.A.

Katsunuma: Established from several isofemale lines caught in Katsunuma, Japan by Prof. T. Watanabe in 1987.

Tai: Established from several dozen isofemale lines caught in 1988 in Ivory Coast by Dr D. Lachaise.

Balancer: SM1/Pm; TM2/Sb. SM1 is marked with $\mathrm{Cu}$; and TM2 is marked with $U b x$.

olfC ${ }^{x 5}$, olf ${ }^{x 17}$ : Two EMS-induced mutant alleles of the $\mathrm{X}$ chromosome olfC gene isolated in the laboratory of Prof. O. Siddiqi. Larvae from both strains show a reduced response to iso-pentyl acetate (Ayyub et al., 1990).

Indifferent $A$, IndifferentB: Two EMS-induced III chromosome mutant strains, isolated in our laboratory. IndfB larvae are totally anosmic to nonanol; IndfA larvae show a wild-type, slight repulsion at low doses (Cobb et al., 1992).

All strains were reared on normal Drosophila medium and kept at $25^{\circ} \pm 0.5^{\circ} \mathrm{C}$ on a $12: 12$ light:dark cycle. Substitution of chromosomes II and III was carried out using the Balancer strain following Bauer \& Sokolowski (1985). In order to substitute the $Y$ chromosome, both reciprocal crosses (male $\times$ female and female $\times$ male) were made in the $F_{4}$ of the protocol.

\section{(b) Preparation of larvae}

Adult females were allowed to lay eggs for $4 \mathrm{~h}$ on a 2.5 per cent agar medium ( 1 per cent acetic acid and 2 per cent ethanol). $24 \mathrm{~h}$ later the hatched larvae were provided with a thick yeast paste for food. After $48 \mathrm{~h}$ of feeding, larvae were tested in the olfactory paradigm. Prior to testing, larvae were washed from the yeast paste and starved on a clean agar dish for between 1 and $2 \mathrm{~h}$. For tests of developmental effects, adults were allowed to lay for only $2 \mathrm{~h}$, and larvae were tested following 16-104 h of feeding.

\section{(c) Olfactory tests}

A modified version of Aceves-Piña and Quinn's (1979) method was used, as described in Cobb et al. (1992). Between 20 and 70 larvae were placed in the centre of a petri dish covered with $10 \mathrm{cl}$ of 2.5 per cent agar. On either side of the petri dish, a $1 \mathrm{~cm}$ circle of filter paper was placed on the agar. Between $0.01 \mu \mathrm{L}$ and $2.5 \mu \mathrm{L}$ of the undiluted odourant was loaded on to one of the filter papers. The lid of the petri dish was replaced, and after 5 min the numbers of larvae on either side of the dish were noted, together with the number which did not 'choose' either side. A simple response index $(\mathrm{RI})$ was calculated for each dish $\left(\left(n^{\text {ollour }}-n^{\text {control }} / n^{\text {total }}\right) \times 100\right)$. This index varies between -100 (total repulsion) and +100 (total attraction). Stimulus/control sides were rotated from dish to dish in all cases. Unless otherwise stated, at least eight dishes were observed for each data point, spread over more than 1 day. Means and standard errors were calculated on the basis of the number of dishes observed for each data point. Larval responses in this test are (a) clearly due to olfaction, not gustation (Cobb et al., 1992); (b) reach a maximum at 5 min and decline thereafter (Rodrigues, 1980) and (c) are not affected by the number of larvae tested (Monte et al., 1989).

In tests where more than one genotype was tested at the same time (e.g. males and females), the following procedure was adopted. After 5 min of testing, the agar was divided into two halves (odour and control) and the agar and larvae from each half were transferred to separate tubes containing Drosophila food. Separate response indices for the two genotypes were then calculated based on the number of adults of each genotype eclosing in each of the classes of tubes.

A series of eight homologous $n$-aliphatic acetates was studied (methyl... octyl acetate; $\mathrm{C}_{3}-\mathrm{C}_{10}$ ) together with cis-vaccenyl acetate $\left(\mathrm{C}_{18}\right)$. All chemicals were from Merck except for heptyl acetate and cis-vaccenyl acetate, which were from Sigma. All chemicals were synthesis grade. Dilutions were not used, because of varying solubility factors (Patte et al., 1982). In both this method and the original procedure of Aceves-Piña \& Quinn (1979), variations in volatility and molecular weight mean that the number of molecules reaching each individual larva when stimulated with, for example, octyl acetate is far less than for methyl acetate.

\section{Results}

\section{(a) Strain differences in acetate-induced olfactory responses}

Canton-S (C), Tai (T) and Katsunuma (K) larvae were tested with a homologous series of eight esters (methyl...octyl acetate) at five volumes $(2.5,1.0,0.5$, 0.1 and $0.05 \mu \mathrm{L}$ ) (Figs 1, 2). An ANOVA revealed a small significant difference between the overall responses of $\mathrm{C}$ and Katsunuma larvae $\left(F_{1,560}=4.27, P<0.05\right)$. However, this result was solely because of the effect of hexyl acetate, which induced repulsion in $\mathrm{C}$ larvae but to which Katsunuma larvae were indifferent at all volumes tested here (Fig. 2). When the data for hexyl acetate were excluded from the ANOVA, the effect was 

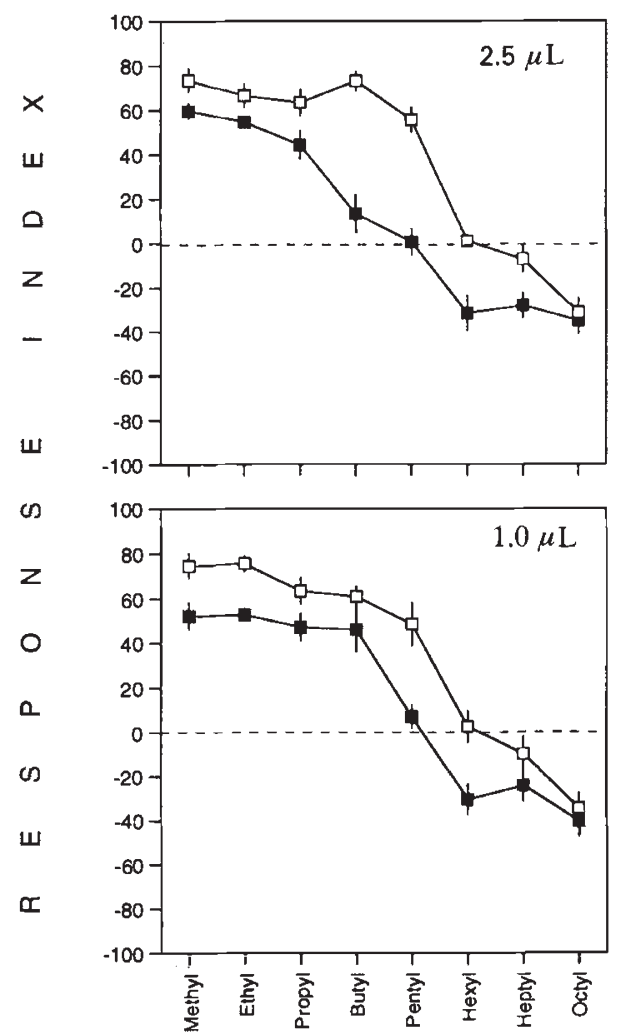

ACETATES
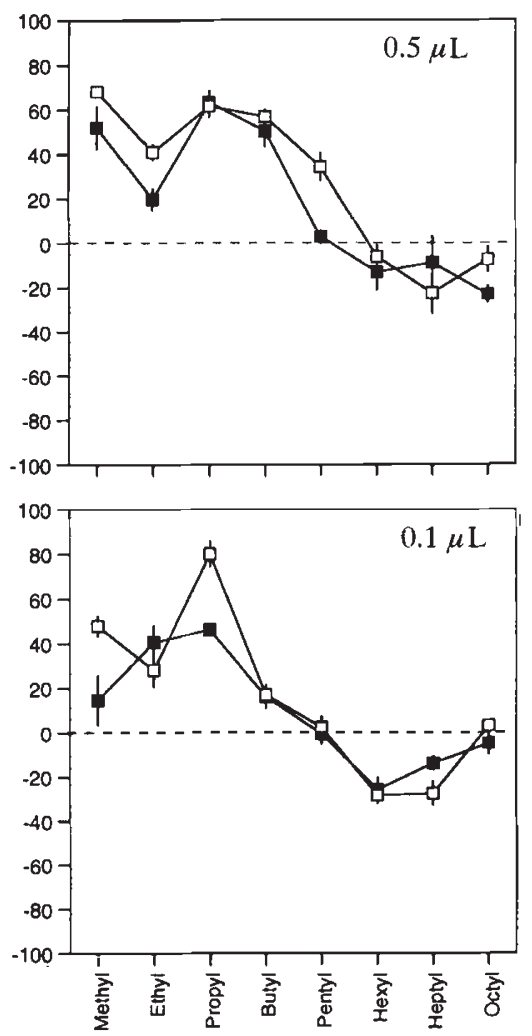

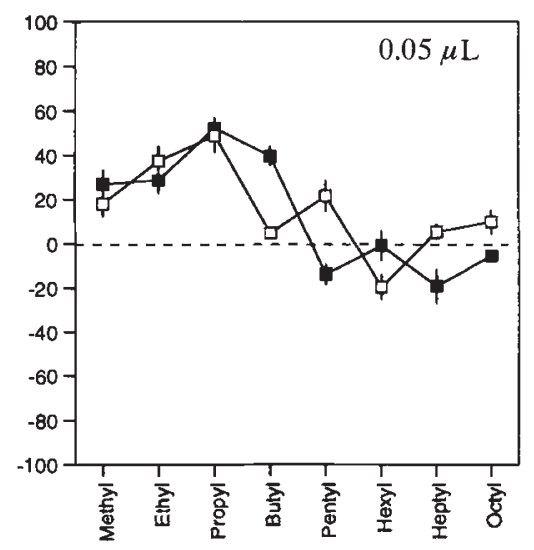

Fig. 1 Mean olfactory response indices of Canton-S (C, open squares) and Tai (T, filled squares) strains of Drosophila melanogaster larvae to methyl... octyl acetate, at five volumes $(2.5-0.05 \mu \mathrm{L})$. Each point represents eight replications. Error bars give standard errors.

no longer significant. For the sake of clarity, therefore, only data for $\mathrm{C}$ and Tai are shown in Fig. 1.

In general, larvae of all three strains were attracted to short-chain acetates, and were either indifferent or repulsed by odours with longer chains. At the two highest volumes studied here, Tai, Katsunuma and C showed similar response profiles, although Tai larvae showed a consistently lower response for all substances, except for octyl acetate. This strain difference was highly significant over all five volumes studied $\left(F_{1,560}=102.15, P=0.0001\right)$.

Most substances induced clear dose-dependent responses, with short-chain acetates (methyl...pentyl) tending to be highly attractive at high doses and less attractive at lower doses. Propyl acetate was exceptional in that all three strains showed no reduction in their attraction, even at the lowest dose studied here. C and Tai larvae showed no significant dose-response effects $\left(\mathrm{C}, r=0, t_{34}=0.00, \mathrm{~T}, r=-0.19, t_{34}=1.13\right)$. K larvae showed a significant negative correlation between stimulus volume and attraction, with lower doses being more attractive than higher doses $(K$, $\left.r=-0.53, t_{34}=3.62, P<0.01\right)$. Heptyl acetate was generally mildly repulsive at all doses, whilst octyl acetate was repulsive at high volumes and induced no response at low volumes, with all three strains showing similar responses.

Qualitative differences were found for responses to two substances. Firstly, as previously noted, Katsunuma larvae were indifferent to hexyl acetate at all doses studied here, whereas $\mathrm{C}$ larvae were generally repelled by this substance. The difference between $\mathrm{C}$ and $\mathrm{K}$ was strongest at $0.1 \mu \mathrm{L}$ (Fig. 2). Secondly, $\mathrm{C}$ and $\mathrm{K}$ larvae showed a dose-dependent attraction to pentyl acetate, whereas Tai larvae were indifferent to this substance at all the volumes tested here (Fig. 2). This apparent anosmia of Tai larvae was highly significant: when the responses of $\mathrm{C}$ and Tai larvae to all eight acetates were taken together, there was a significant strain $\times$ substance interaction $\quad\left(F_{7,560}=4.92\right.$, $P=0.0001)$. However, if the data for pentyl acetate were excluded, this effect was no longer significant $\left(F_{6,490}=0.77, P=\mathrm{NS}\right)$, although the overall strain difference remained. 


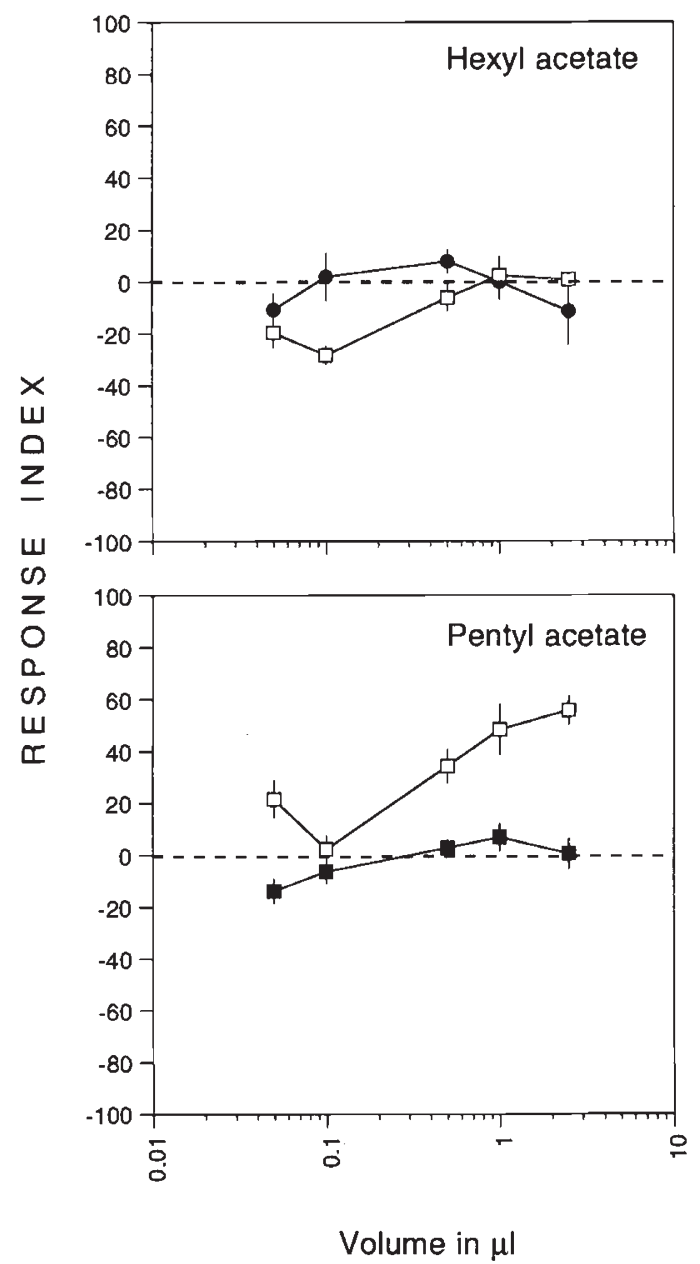

Fig. 2 Dose-response curves for olfactory response indices of Canton-S (open squares) and Katsunuma (filled circles) larvàe to hexyl acetate (upper panel); and for Canton-S (open squares) and Tai (filled squares) larvae to pentyl acetate (lower panel).

All three strains were also tested with cis-vaccenyl acetate $\left(\mathrm{C}_{18}\right)$ at the same five volumes. No strain differences were found; all three strains showed a very slight attraction at $2.5 \mu \mathrm{L}$ (mean RIs: C, 9.27 4.6; T, $9.10 \pm 4.7$ and $K, 17.13 \pm 9.3$ ), a slight reduction at 1 $\mu \mathrm{L}$, with no significant responses at the three lower volumes.

\section{(b) Developmental changes in the olfactory response to acetates}

C, Katsunuma and Tai larvae were tested with $2.5 \mu \mathrm{L}$ of ethyl, propyl and pentyl acetate at between 18 and $98 \mathrm{~h}$ after their first contact with food (Fig. 3). Differences were observed between strains and substances. The responses of all three strains to ethyl acetate showed a significant decline with age, although the effect was clearly weaker in the case of Tai (see caption to Fig. 3 for details). The responses of Tai larvae to propyl acetate and pentyl acetate showed no significant changes with age; the anosmia of Tai larvae in response to pentyl acetate was constant throughout larval life. Both $\mathrm{C}$ and $\mathrm{K}$ larvae, however, showed significant declines in their responses to propyl acetate. For pentyl acetate, only $\mathrm{C}$ showed a significant decline, the response of $\mathrm{K}$ larvae showing no significant changes with age. None of the age effects appeared to be directly linked to larval instar.

\section{(c) Genetic control of the response to hexyl acetate}

The qualitative difference in the response to hexyl acetate shown by $\mathrm{C}$ and Katsunuma larvae (Fig. 2) was investigated. Reciprocal hybrid larvae were made between the two strains and tested with $0.1 \mu \mathrm{L}$ of hexyl acetate. Both hybrids showed responses which were not significantly different from each other and which were intermediate between the two parental strains (Table 1, lines 3 and 4). No differences were found between the responses of males and females from the two reciprocal hybrids (data not shown). These data strongly indicate an autosomal effect with no clear dominance. Chromosomes II and III were then substituted between the two strains. The reconstituted $\mathrm{C}$ and $\mathrm{K}$ strains showed the same phenotypes as the parental strains (Table 1, lines 1 and 2 vs. lines 5 and 8 ), with no significant effect due to the chromosomal substitution procedure. There was a highly significant effect of chromosome II $\left(F_{1,60}=35.46, P<0.001\right)$, with strains having a $\mathrm{C}$ chromosome II showing repulsion to hexyl acetate, whereas those with a Katsunuma chromosome II were indifferent (Table 1, lines 5 and 6 vs. lines 7 and 8).

\section{(d) Genetic control of the response to pentyl acetate}

The genetic basis of the anosmia of Tai in response to pentyl acetate (Fig. 2) was investigated. Reciprocal hybrids were made between the $\mathrm{C}$ and Tai strains (Table 2); both reciprocal hybrids were attracted to 2.5 $\mu \mathrm{L}$ of pentyl acetate, but there was a significant difference between the two types $\left(t_{14}=2.66, P<0.05\right)$, with larvae from the Tai female $\times \mathrm{C}$ male cross showing a significantly weaker response than either the reciprocal hybrid or the $\mathrm{C}$ parent phenotype $\left(t_{22}=3.03, P<0.01\right)$, which in turn were not significantly different from each other $\left(t_{22}=1.42\right)$.

The fact that $\mathrm{T} \times \mathrm{C} \mathrm{F}_{1}$ hybrids showed a response which was quantitatively roughly intermediate between those of the two parent strains, whereas $\mathrm{C} \times \mathrm{T} \mathrm{F}_{1}$ hybrids were similar to the $\mathrm{C}$ parents, suggested that 
Ethyl acetate
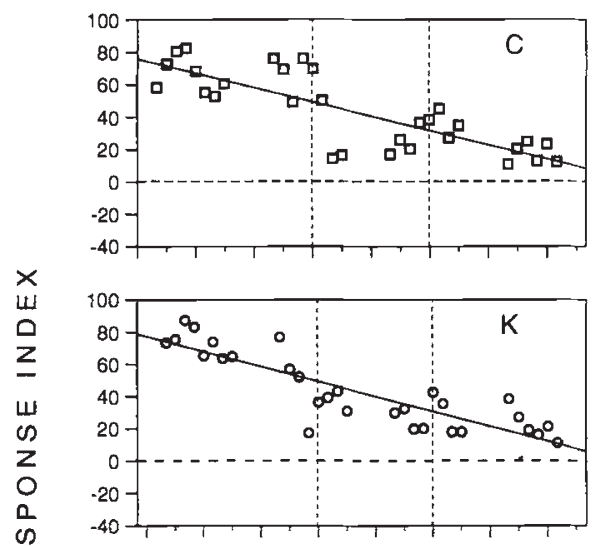

$\underset{\square}{W}$

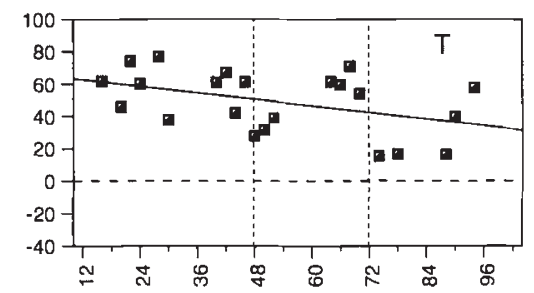

Propyl acetate
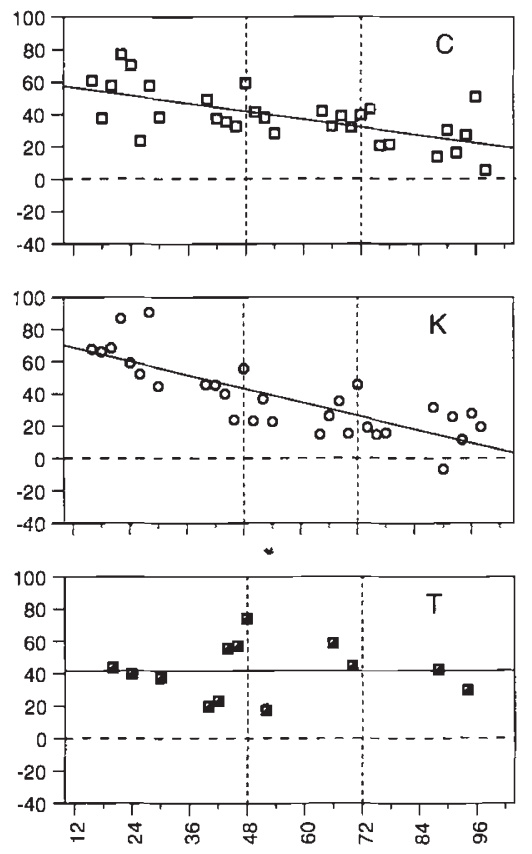

Pentyl acetate
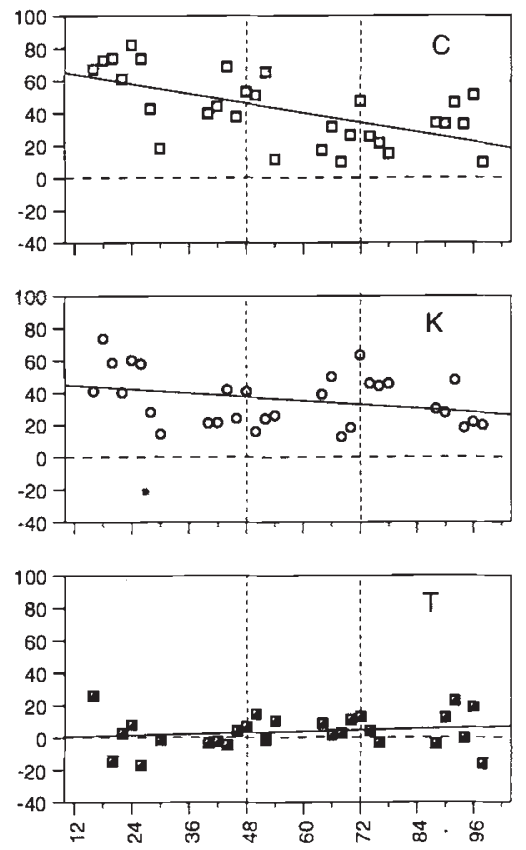

HOURS AFTER FIRST FEEDING

Fig. 3 Mean olfactory response indices of Canton-S (C), Katsunuma (K) and Tai (T) larvae to $2.5 \mu \mathrm{L}$ ethyl, propyl and pentyl acetate over developmental time. Time $0=$ first larval contact with food, at most $2 \mathrm{~h}$ after larval eclosion. Vertical lines represent approximate divisions between larval instars. Each point represents between two and eight replications. Linear regression lines are included. The correlation coefficients and significance levels were as follows. Ethyl acetate: $\mathrm{C}, r=-0.808, t_{28}=7.28$, $P<0.001 ; \mathrm{K}, r=-0.869, t_{28}=9.29, P<0.001 ; \mathrm{T}, r=-0.439, t_{21}=2.17, P<0.05$. Propyl acetate: $\mathrm{C}, r=-0.647, t_{28}=4.49$, $P<0.001 ; \mathrm{K}, r=-0.80, t_{28}=7.06, P<0.001 ; \mathrm{T}, r=0.00, t_{11}=0$, NS. Pentyl acetate: $\mathrm{C}, r=-0.607, t_{28}=4.05, P<0.001 ; \mathrm{K}$, $r=-0.316, t_{28}=1.76, \mathrm{NS} ; \mathrm{T}, r=-0.158, t_{25}=0.8, \mathrm{NS}$.

Table 1 Genetic control of the olfactory response in Drosophila melanogaster larvae to $0.1 \mu \mathrm{L}$ hexyl acetate

\begin{tabular}{|c|c|c|c|c|c|c|}
\hline \multirow[b]{2}{*}{ Line } & \multirow[b]{2}{*}{ Strain } & \multicolumn{2}{|c|}{ Chromosome } & \multirow[b]{2}{*}{$n$} & \multirow[b]{2}{*}{ Response index } & \multirow[b]{2}{*}{$\mathrm{SE}$} \\
\hline & & II & III & & & \\
\hline 1 & C Parental & & & 8 & -28.27 & 3.43 \\
\hline 2 & K Parental & & & 8 & 2.06 & 9.06 \\
\hline 3 & $\mathrm{~F} 1\left(\mathrm{C} Q \times \mathrm{Ko}^{\circ}\right)$ & & & 6 & -13.70 & 4.60 \\
\hline 4 & $\mathrm{~F} 1\left(\mathrm{~K} q \times \mathrm{Co}^{0}\right)$ & & & 7 & -19.30 & 8.00 \\
\hline 5 & K Reconstituted & $\mathrm{K}$ & $\mathrm{K}$ & 16 & 0.42 & 5.98 \\
\hline 6 & Substituted & K & $\mathrm{C}$ & 16 & 0.76 & 4.10 \\
\hline 7 & Substituted & $\mathrm{C}$ & $\mathrm{K}$ & 16 & -25.05 & 2.74 \\
\hline 8 & C Reconstituted & $\mathrm{C}$ & $\mathrm{C}$ & 16 & -22.24 & 2.49 \\
\hline
\end{tabular}

Mean response indices and standard errors.

$n$, number of tests.

20-70 larvae were observed in each test. 
Table 2 The role of the $\mathrm{X}$ chromosome in the olfactory response to $2.5 \mu \mathrm{L}$ pentyl acetate

\begin{tabular}{|c|c|c|c|c|}
\hline Line & Strain & $n$ & Response index & SE \\
\hline 1 & $\mathrm{C}$ & 16 & 49.10 & 4.51 \\
\hline 2 & Tai & 16 & 4.17 & 3.83 \\
\hline 3 & $\mathrm{~F} 1\left(\mathrm{C} \& \times \mathrm{T} \mathbf{O}^{\prime}\right)$ & 8 & 39.16 & 3.95 \\
\hline 4 & $\mathrm{~F} 1(\mathrm{~T} \% \times \mathrm{CO})$ & 8 & 28.66 & 2.88 \\
\hline 5 & $\mathrm{~F} 1 \% q(\mathrm{C} \times \mathrm{T})$ & (367) & 32.04 & - \\
\hline 6 & $\mathrm{~F} 1 \uparrow q(\mathrm{~T} \times \mathrm{C})$ & (208) & 30.88 & - \\
\hline 7 & $\mathrm{~F} 1$ రొర $(\mathrm{C} \times \mathrm{T})$ & (369) & 31.70 & - \\
\hline 8 & $\mathrm{~F} 10^{\circ} \mathbf{O}^{\circ}(\mathrm{T} \times \mathrm{C})$ & (155) & -3.23 & - \\
\hline
\end{tabular}

Response indices are means for lines 1-4 and totals, based on the numbers of eclosed adults, for lines 5-8 (see Materials and methods for explanation).

$n$, number of tests for lines 1-4 and (in parentheses) total number of eclosed adults for lines 5-8.

Between 20 and 70 larvae were observed in each test.

there may be an X chromosome effect. This was confirmed by calculating separate response indices for males and females of the two reciprocal hybrids, based on the total number of male and female flies eclosing following testing (Table 2). Although the $\mathrm{C} \times \mathrm{T}$ cross produced a near-perfect sex-ratio (367:369 females:males), the reciprocal cross showed a significant deficit of males $\left(208: 155, \chi_{1}^{2}=7.78, P<0.01\right)$, probably indicating the existence of a significant lethality in this cross.

There was no significant difference between the two reciprocal female types for the number of individuals attracted and repulsed by pentyl acetate $\left(\chi_{1}^{2}=1.32\right)$. However, there was a significant difference between the two reciprocal male types $\left(\chi_{1}^{2}=13.88, P<0.001\right)$. As can be seen from Table 2 , the reduction in the response of the $\mathrm{T} \times \mathrm{C}$ hybrids was entirely due to the apparent indifference shown by $\mathrm{T} \times \mathrm{C}$ males. $\mathrm{T} \times \mathrm{C}$ females showed a response index which was virtually identical to those of $\mathrm{C} \times \mathrm{T}$ males and females, suggesting that maternal factors do not play a role. These results show that there are gene(s) on the $\mathrm{X}$ chromosome controlling the response to pentyl acetate and that the $\mathrm{C}$ form is dominant over Tai.

In order to detect whether any other chromosomes were involved in modulating the response to pentyl acetate, the II and III chromosomes were substituted between the strains using a double balancer strain carrying SM1 and TM2. This ensures that all strains have the same $\mathrm{X}$ chromosome, that from the Balancer strain which had a Tai-like phenotype. In addition, differences between the $\mathrm{Y}$ chromosomes from the two strains were also tested (see Materials and methods for details). The results for all strains are shown in Table 3.

The reconstituted $\mathrm{C}$ strain (Table 3 , line 8 ) showed a lower mean response than the parental strain $(\mathrm{RI}=33.32$ as against 49.104$)$, but this difference was not significant $\left(t_{30}=1.89\right)$. The reconstituted $\mathrm{T}$ strain (Table 3, line 13) showed a typical Tai-like anosmia and was not significantly different from the parental strain $\left(t_{23}=1.43\right)$. No significant effect of the $\mathrm{Y}$ chromosome was found, nor were any consistent nonsignificant differences observed in the mean responses of the exchanged strains differing only by their $\mathrm{Y}$ chromosomes (Table 3, lines 9 vs. 10 and 11 vs. 12). For subsequent analysis, the data from these strains were pooled. These data show that, given the presence of a Balancer-strain $\mathrm{X}$ chromosome in all the strains produced by the chromosome substitution, autosomal genes can also qualitatively control the response to pentyl acetate.

From the $\mathrm{F}_{3}$ strains onward (Table 3 , lines 4 and 5) it was apparent that there was a strong effect of chromosome III. This was confirmed by a two-way ANOVA on all exchanged strains (Table 3, lines 8, 9+10, 11+12 and 13 ) which clearly showed a highly significant effect of chromosome III $\left(F_{1,69}=88.62, P=0.0001\right)$. There was no significant effect of chromosome II $\left(F_{1,69}=1.09\right)$, but there was a slightly significant interaction between the two chromosomes $\left(F_{1,69}=4.36, \quad P=0.043\right)$. This effect was due to the relatively higher mean response of $\mathrm{T} ; \mathrm{C}$ larvae as compared to $\mathrm{C} ; \mathrm{C}(\mathrm{RI}=47.88$ vs. 33.32 ; Table 3 , lines $8+10$ and $11+12$ pooled). This suggests that although in the context of a Balancer $\mathrm{X}$ chromosome the response to pentyl acetate is qualitatively controlled by genes on chromosome III, characters on chromosome II quantitatively modulate this phenotype.

This finding was supported by a comparison of the effects of the Tai and Balancer chromosomes II and III. An ANOva on the data shown in Table 3 lines 3, 4, 6 and 13 revealed a significant effect on chromosome II $\left(F_{1,30}=5.07, P<0.05\right)$, with no significant effect of chromosome III and no significant interaction. Larvae with a B chromosome II showed a slight repulsion $(\mathrm{RI}=-3.03)$, whereas larvae with a Tai chromosome II were slightly attracted $(\mathrm{RI}=6.12)$.

In order to determine the dominance of the characters on the II and III chromosomes, crosses were made between the various exchanged strains, and the olfactory responses of the resultant $F_{1}$ were tested (Table 4). The presence of a single Tai chromosome III was sufficient to produce an anosmia (Table 4, line 2), indicating that the Tai autosomal character(s) controlling the response to pentyl acetate are dominant over 
Table 3 The role of chromosomes II and III and of the Y chromosome in the olfactory response to $2.5 \mu \mathrm{L}$ pentyl acetate

\begin{tabular}{rcrrrrrr}
\hline & & \multicolumn{9}{c}{ Chromosome } & & \\
\cline { 3 - 5 } Line & Strain & II & III & Y & $n$ & Response index & SE \\
\hline \multirow{2}{*nnyyyynn}{1} & C Parental & C & C & C & 16 & 49.10 & 4.51 \\
2 & T Parental & T & T & T & 16 & 4.17 & 3.83 \\
3 & Balancer & B & B & B & 9 & 4.73 & 7.70 \\
4 & F $_{3}$ & B & T & T & 6 & -14.66 & 9.94 \\
5 & F $_{3}$ & B & C & C & 10 & 40.43 & 5.60 \\
6 & F $_{3}$ & T & B & T & 10 & 16.94 & 8.00 \\
7 & F $_{3}$ & C & B & C & 10 & 3.93 & 7.70 \\
8 & C Reconstituted & C & C & C & 16 & 33.32 & 7.05 \\
9 & Substituted & T & C & C & 12 & 45.96 & 6.57 \\
10 & Substituted & T & C & T & 16 & 49.32 & 3.49 \\
11 & Substituted & C & T & C & 14 & -1.70 & 3.85 \\
12 & Substituted & C & T & T & 6 & 0.21 & 3.67 \\
13 & T Reconstituted & T & T & T & 9 & -5.90 & 6.57 \\
\hline
\end{tabular}

Response indices are means.

Between 20 and 70 larvae were observed in each test. $n$, number of tests; SE, standard error; C, Canton-S; T, Tai; B, Balancer $(\mathrm{SM} 1 / \mathrm{Pm} ; \mathrm{TM} 2 / \mathrm{Sb}) ; \mathrm{F}_{3}, \mathrm{~F}_{3}$ strains from Bauer \& Sokolowski's (1985) protocol, carrying one homologous pair of chromosomes from the strain to be substituted, the other pair coming from the Balancer strain.

All strains apart from the parental lines share the X chromosome from the Balancer strain. See Materials and methods for further details. Data for the two parental strains are from Table 2.

Table 4 Dominance effects on the olfactory response to 2.5 $\mu \mathrm{L}$ pentyl acetate

\begin{tabular}{|c|c|c|c|c|c|}
\hline \multirow[b]{2}{*}{ Line } & \multicolumn{2}{|c|}{ Chromosome } & \multirow[b]{2}{*}{$n$} & \multirow[b]{2}{*}{ Response index } & \multirow[b]{2}{*}{ SE } \\
\hline & II & III & & & \\
\hline 1 & $\frac{\mathrm{T}}{\mathrm{C}}$ & $\frac{\mathrm{C}}{\mathrm{C}}$ & 8 & 52.00 & 5.36 \\
\hline 2 & $\frac{\mathrm{C}}{\mathrm{C}}$ & $\frac{\mathrm{T}}{\mathrm{C}}$ & 12 & 3.68 & 4.89 \\
\hline 3 & $\frac{\mathrm{T}}{\mathrm{C}}$ & $\frac{\mathrm{T}}{\mathrm{C}}$ & 10 & 6.90 & 5.47 \\
\hline
\end{tabular}

Mean response indices plus standard errors. $n$, number of tests.

the $\mathrm{C}$ form $(\mathrm{s})$. Significant differences were found according to whether there were 0,1 or $2 \mathrm{C}$ second chromosome present (Table 3, lines 9 and 10; Table 4, line 1; and Table 3, line 8; $F_{2,49}=3.67, P=0.03$ ). The responses of larvae homozygous for $\mathrm{C}$ chromosome II (C/C) were significantly lower than $\mathrm{T} / \mathrm{C}$ or $\mathrm{T} / \mathrm{T}$ larvae, which in turn were not significantly different from each other, indicating that the modulating factor on the Tai chromosome II is dominant over the $\mathrm{C}$ form.

\section{(e) Responses of olfactory mutants}

Larvae from strains carrying two alleles $(x 5, x 17)$ of the $\mathrm{X}$ chromosome olfactory mutant olfC which show a reduced response to iso-pentyl acetate (Ayyub et al., 1990) were tested with all nine acetates. The response profiles of the two mutant strains to the four acetates with the shortest chains (methyl, ethyl, propyl and butyl acetate), the two longest chains (heptyl and octyl acetate) and $c i s$-vaccenyl acetate were not significantly different from the responses of $\mathrm{C}$ when tested by ANOVA, nor were there any significant strain $\times$ substance interactions (data not shown).

Dose-response curves of the two olfC alleles when stimulated with pentyl and hexyl acetate are shown in Fig. 4, together with the responses of $\mathrm{C}$ larvae taken from Fig. 1. When stimulated with pentyl acetate, larvae with both olfC alleles showed the same overall 
response profile as $\mathrm{C}$ larvae, but with a consistently lower response, including repulsion at $0.05 \mu \mathrm{L}$ in the case of olfC $\mathrm{C}^{x}$. A significant difference between the two alleles was found for hexyl acetate. olf ${ }^{x / 7}$ larvae were repulsed at high volumes and indifferent at low volumes, the inverse of the $\mathrm{C}$ response. olf ${ }^{.5}$ larvae barely showed any significant response at any volume.

Larvae from two mutant strains, IndfA and IndfB, which do not respond to nonanol $\left(C_{9}\right)$, were tested with $2.5 \mu \mathrm{L}$ of each of the eight homologous acetates. No significant differences were found compared with the responses of $\mathrm{C}$ larvae, except for the responses to heptyl acetate $\left(\mathrm{C}_{9}\right)$, for which the two strains showed parallel responses: slight attraction at low doses and a slight repulsion at $2.5 \mu \mathrm{L}$. Dose-response curves for

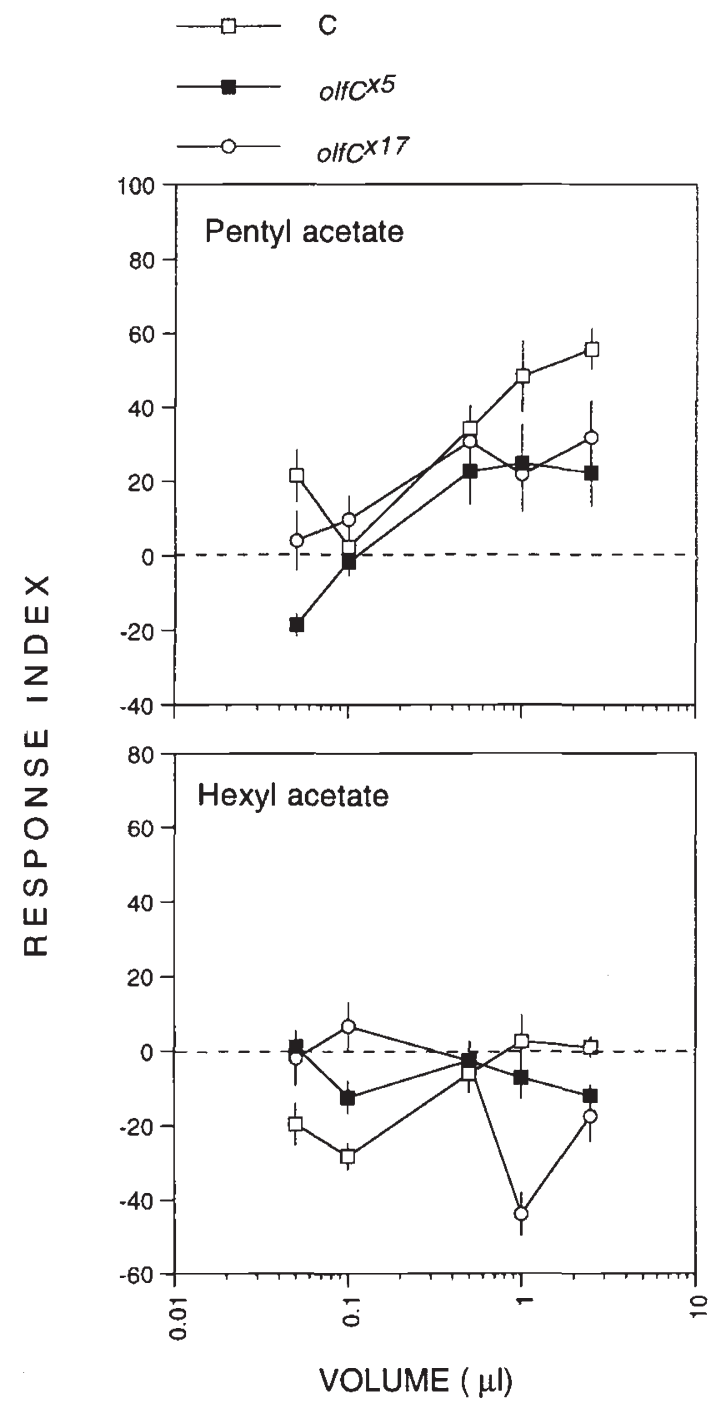

Fig. 4 Mean olfactory response indices of two olfactory mutants $\left(\right.$ olf $C^{x 5}$ and olf $\left.C^{x / 7}\right)$ and of Canton-S $(\mathrm{C})$ following stimulation with varying doses of pentyl and hexyl acetate. Error bars show standard errors. the response to heptyl acetate at 2.5, 1.0, 0.5, 0.1 and $0.01 \mu \mathrm{L}$ are shown in Fig. 5, together with the data for C from Fig. 1.

\section{Discussion}

The data presented here show that Drosophila larvae can detect a number of different aliphatic acetates. Short-chain acetates (methyl...pentyl acetate, $\mathrm{C}_{3}-\mathrm{C}_{7}$ ) generally attracted larvae, with the response to propyl acetate $\left(\mathrm{C}_{5}\right)$ being particularly strong, showing no dose-response effect at the volumes studied here. Longer-chain acetates (hexyl, heptyl and octyl acetate) showed dose-dependent repellent effects in most strains. Similar results have recently been found for the nematode Caenorhabditis elegans, where methyl...pentyl acetate were found to be attractive, and hexyl acetate was neutral (Bargmann et al., 1993). It is also interesting to note that electroantennogram responses of the tephritid fruit fly, Rhagoletis pomonella, are low with ethyl, propyl and butyl acetate, slightly higher with pentyl, hexyl and octyl acetate, and maximal with heptyl acetate (Averill et al., 1988) and that electrophysiological responses of dogs and box turtles are strongest in response to butyl, pentyl and hexyl acetate and decline rapidly thereafter (Tonosaki \& Tucker, 1982). Similar results with regard to chainlength have been found for the response of Drosophila larvae to alcohols (Cobb et al., 1992).

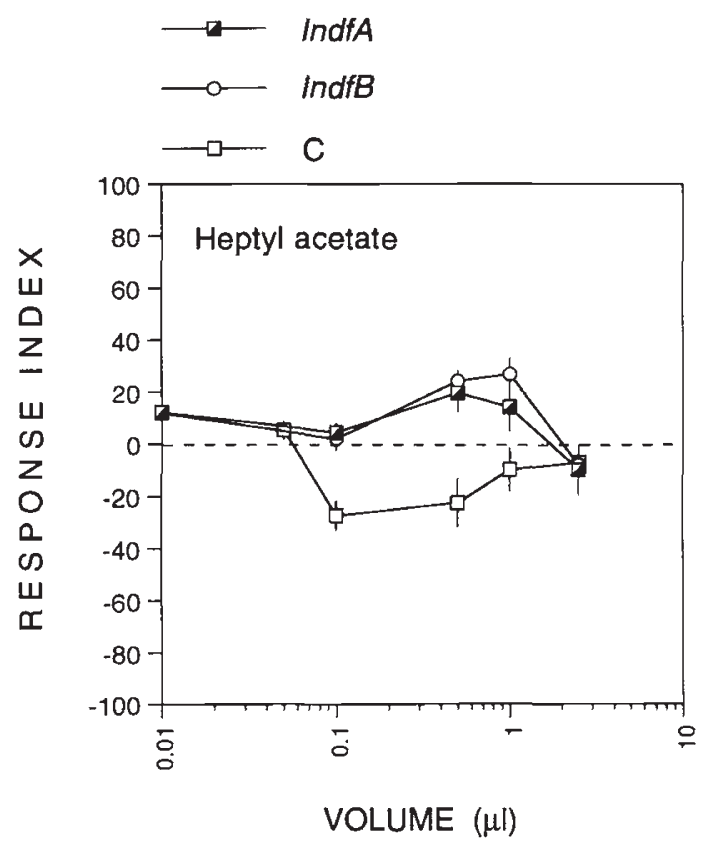

Fig. 5 Mean olfactory response indices of two olfactory mutants (Indifferent $A$ and Indifferent $B$ ) and of Canton-S $(C)$ following stimulation with varying doses of heptyl acetate. Error bars show standard errors. 
The differing dose-response curves produced by stimulation with different acetates show clearly that Drosophila larvae can detect all these substances and that there is more than one class of receptor for acetates in Drosophila larvae. There appears to be a high affinity site for propyl acetate and at least one weaker affinity site for the longer-chain, repulsive acetates, although the specificity of the II chromosome anosmia to hexyl acetate shown by Katsunuma larvae and the abnormal response of the Indf anosmic larvae to heptyl acetate suggest that there is more than one long-chain, repellent site. These data support electrophysiological and mutant studies of adult Drosophila which strongly suggest that there are at least two separate acetate receptors in adult flies, one which can detect ethyl acetate, and another which can detect pentyl acetate (Siddiqi, 1983, 1987; Ayyub et al., 1990).

Genes affecting olfaction were found on three of the four chromosomes studied. The absence of any effect of the Y chromosome was not surprising, given the fact that this chromosome is largely genetically silent and that all the known genes on the chromosome are related to sperm anatomy or physiology (Lindsley and Zimm, 1992). The fact that this study - relatively limited in terms of stimulus molecules and genetic variants - has revealed at least one factor involved in olfaction on each of the three remaining chromosomes studied suggests that further studies of larval olfation will probably lead to the discovery of other genes involved in these or other olfactory pathways.

It would be tempting to interpret the specific anosmias described here as a consquence of mutations in unique receptor molecules. However, in all cases the situation is more complex. The Katsunuma strain showed a specific anosmia in response to hexyl acetate $\left(\mathrm{C}_{8}\right)$, which repelled $\mathrm{C}$ larvae. This character was localized to chromosome II (Table 1). However, Katsunuma larvae also show an anosmia when stimulated with heptanol $\left(\mathrm{C}_{7}\right)$, which is normally attractive (Cobb et al., 1992). This factor is also located on chromosome II. It is possible that the two phenotypes are coded for by the same gene(s), which affect structures which detect a common 'odour primitive' involved in the perception of both substances. Further genetic and behavioural analyses will be necessary to resolve this problem.

olf $C^{x 5}$ and olf $C^{17}$ have previously been reported to show reduced responses to iso-pentyl acetate and ethyl acetate (Ayyub et al., 1990). We found altered responses of these two mutants to both $n$-pentyl acetate and hexyl acetate (Fig. 4), suggesting that the mutation affects some element of chemodetection which is common to all three substances. As well as sharing their acetate function, the three substances have similar numbers of carbons ( 7 and 8 ) but differ in chain length (2-4 carbons respectively). Given the different responses of the three wild-type strains to pentyl and hexyl acetate, and the fact that the Katsunuma larvae were indifferent to hexyl acetate but responded normally to pentyl acetate, either the two substances are detected separately at the peripheral level - i.e. they have separate receptors - or they can be distinguished by some central, integrative function.

Finally, we found that the two Indifferent mutants showed abnormal responses to heptyl acetate $\left(\mathrm{C}_{9}\right) /$ Fig. 5); these two strains were isolated on the basis of their anosmia when stimulated with nonanol $\left(\mathrm{C}_{9}\right)$ (Cobb et al., 1992). IndfA adults are also highly resistant to actanoic acid $\left(\mathrm{C}_{8}\right)$ which rapidly kills wild-type flies (L. Legal, in preparation). The fact that these pleiotropic effects are all expressed with regard to similar chain-lengths suggests that the mutation(s) may affect a mechanism involved in the detection of chain-length.

The most complex genetic result found was that for pentyl acetate, where two characters were found which qualitatively controlled the response, one on the $\mathrm{X}$ chromosome (Table 2) and one on chromosome III (Table 3). Quantitative variation of the response was influenced by chromosome II. The C X chromosome has a clear epistatic effect on the characters on chromosome III: $\mathrm{F}_{1}$ hybrid females, with one $\mathrm{C} \mathrm{X}$ chromosome and one $\mathrm{C}$ third chromosome, were able to respond to pentyl acetate (Table 2, lines 5 and 6), whereas larvae with one $\mathrm{C}$ third chromosome but homozygous for the Balancer $\mathrm{X}$ chromosome could not (Table 4, lines 2 and 3). The genes on the two chromosomes cannot both code for a unique and specific pentyl acetate receptor; the most likely interpretation is that they code different components of a structure devoted at least in part to the detection of pentyl acetate.

To complete the picture of a complex genetic determinism of the response to pentyl acetate, the Tai II chromosome significantly increased the response to pentyl acetate in strains homozygous for a $\mathrm{C}$ chromosome III, indicating the presence of modifier genes on this chromosome. This is not the first time that this kind of result has been reported: Fuyama (1978) found genetic variation for adult responses to ethyl acetate on chromosome II, with nonspecific modifier genes on chromosome III.

The slight attraction of larvae of all three wild-type strains when stimulated with cis-vaccenyl acetate should not be taken as indicating that this substance has a pheromonal role for larvae. The responses were extremely weak, and the dose levels extremely high, corresponding to the cis-vaccenyl acetate content of several thousand males. It is at least possible that the 
larvae were detecting the acetate group in general, rather than the specific combination of acetate group and chain length corresponding to the stimulus molecule.

The olfactory response of wild-type larvae to ethyl acetate has previously been reported to be stable over developmental time (Monte et al., 1989). Cobb et al. (1992) found that the responses to alcohols declined with age. Similar results were obtained in this study for all three acetates tested (Fig. 3). The method used by Monte et al. (1989) was slightly different from that used here, in that they applied a solution of ethyl acetate with a total volume $10 \times$ greater than the maximum volume studied here. This difference in method could have induced the different response of aged larvae found in the two studies. In order to test this possibility, Katsunuma larvae aged 24, 48, 72 and $96 \mathrm{~h}$ were tested using Monte et al.'s (1989) protocol. No significant differences were found from the data presented in Fig. 3 (data not shown). It seems most likely that the difference between our result and that of Monte et al. is due to strain differences.

This study has confirmed the usefulness of Drosophila larvae for the study of the genetic bases of olfaction, by revealing a wide variety of responses and a number of genetic factors. Other genes, as yet undetected, are certainly involved in coding for the larval olfactory response. Three fundamental tasks remain in this domain. The first is to continue this kind of investigation in the hope of mapping the totality of the olfactory response and discovering all the key genes involved in producing this response; the project of saturating the Drosophila olfactory genome, thereby revealing the proportion of genes involved in chemodetection, is far from impossible. The second challenge is to discover the reality of olfactory coding and neuronal function in Drosophila larvae by the use of electrophysiological techniques. Finally, the genetic characters identified by mutagenesis or by chromosome substitution need to be localized, cloned and sequenced in order to bring the tools of molecular genetics to bear on the problem of the exact function of the gene products involved.

\section{Acknowledgements}

Jean-Marc Jallon, Renée Venard and Jean-François Ferveur are thanked for their comments on a previous version of the manuscript.

\section{References}

ACEVES-PINA, E. AND QUINN, w. 1979. Learning in normal and mutant Drosophila larvae. Science, 206, 93-96.
ALCORTA, E. AND RUBIO, J. 1988. Genetical analysis of intrapopulational variation in olfactory response in Drosophila melanogaster. Heredity, 60, 7-14.

AVERILL, A. L., REISSIG, W. H. AND ROELOFS, W. L. 1988. Specificity of olfactory responses in the tephritid fruit fly, Rhagoletis pomonella. Entomologia exp. appl., 47, 211-222.

AYYUB, C., PARANJAPE, J., RODRIGUES, V. AND SIDDIQI, o. 1990. Genetics of olfactory behavior in Drosophila melanogaster. J. Neurogenet., 6, 243-262.

BARGMANN, C. I., HARTWIEG, E. AND HORVITZ, H. R. 1993. Odorant-selective genes and neurons mediate olfaction in C. elegans. Cell, 74, 515-527.

BARrows w. M. 1907. The reactions of the pomace fly Drosophila ampelophila Loew, to odorous substances. J. Exp. Zool., 4, 515-537.

BARTELT, R. J., SCHANER, A. M. AND JACKSON, L. L. 1985. cisVaccenyl acetate as an aggregation pheromone in Drosophila melanogaster. J. Chem. Ecol., 11, 1747-1756.

BAUER, S. J. AND SOKOLOWSKI, M. B. 1985. A genetic analysis of path length and pupation height in a natural population of Drosophila melanogaster. Can. J. Genet. Cytol., 27, 334-340.

BERGER, R. G. 1990. The biogenesis of fruit flavors: a continuing story. Perfumer and Flavorist, 15, 33-39.

BUCK, L. AND AXEL, R. 1991. A novel multigene family may encode odorant receptors: a molecular basis for odor recognition. Cell, 65, 175-187.

CARlson, J. 1991. Olfaction in Drosophila: genetic and molecular analysis. Trends Neurosci., 14, 520-524.

COBB, M., BRUNEAU, S. AND JALLON, J.-M. 1992. Genetic and developmental factors in the olfactory response of Drosophila melanogaster larvae to alcohols. Proc. R. Soc. B., 248, 103-109.

COBB, M., VEnARD, R. AND JALlON, J.-M. 1993. From genes to smell: Studies in olfaction in Drosophila melanogaster. In: Wiese, K., Gribakin, F. G., Popov, A. V. and Renninger G. (eds) Sensory Systems of Arthropods, pp. 462-468. Birkhäuser, Berlin.

FERVEUR, J.-F., COBB, M. AND JALloN, J.-M. 1989. Complex chemical messages in Drosophila. In: Singh, R. N. and Strausfeld, N. J. (eds) Neurobiology of Sensory Systems, pp. 397-409. Plenum, New York.

FUYAMA, Y. 1978. Behavior genetics of Drosophila. II. An odorant specific variant in a natural population of Drosophila melanogaster. Behav. Genet., 8, 375-405.

JALLON, J.-M. 1984. A' few chemical words exchanged by Drosophila during courtship. Behav. Genet., 14, 441-478.

LILLY, M. AND CARLSON, J. 1989. smellblind: a gene required for Drosophila olfaction. Genetics, 124, 293-302.

LINDSLEY, D. L. AND ZIMM, G. G. 1992. The Genome of Drosophila melanogaster. Academic Press, London.

MONTE, P., WOODARD, C., AYER, R., LILLY, M., SUN, H. AND CARLSON, J. 1989. Characterization of the larval olfactory response in Drosophila and its genetic basis. Behav. Genet., 19, 267-283.

MORI, K., MATAGA, N. AND IMAMURA, K. 1992. Differential specificities of single mitral cells in the rabbit olfactory bulb for a homologous series of fatty-acid odor molecules. J. Neurophysiol., 67, 786-789. 
NGAI, J., CHESS, A., DOWLING, M. M., NECLES, N., MACAGNO, E. R. AND AXEL, R. 1993. Coding of olfactory information: topography of odorant receptor expression in the catfish olfactory epithelium. Cell, 72, 667-680.

PATTE, F., ETCHETO, M. AND LAFFORT, P. 1982. Solubility factors for 240 solutes and 207 stationary phases in gas-liquid chromatography. Analyt. Chem., 54, 2239-2247.

RAMING, K., KRIEGER, J., STROTMANN, J., BOEKHOFF, I., KUBICK, S., BAUMSTARK, C. AND BREER, H. 1993. Cloning and expression of odorant receptors. Nature, 361, 353-356.

RODRIGUES, v. 1980. Olfactory behavior of Drosphila melanogaster. In: Siddiqi, O., Babu, P., Hall, L. M. and Hall, J. C. (eds) Development and Neurobiology of Drosophila, pp. 361-372. Plenum Press, London.

SHEPHERD, G. 1991. Computational structure of the olfactory system. In: Davis, J. L. and Eichenbaum H. (eds) Olfaction: a Model System for Computational Neuroscience, pp. 3-41. MIT Press, London.

SIDDIQI, o. 1983. Olfactory neurogenetics of Drosphila. In: Chopra, V. L., Joshi, B. C., Sharma R. P. and Bansal, H. C. (eds) Genetics: New Frontiers, vol. III, pp. 243-261. Oxford University Press, Bombay.
SIDDIQI, o. 1987. Neurogenetics of olfaction in Drosophila melanogaster. Trends Genet., 3, 137-142.

SINGH, R.N. AND SINGH, K. 1984. Fine structure of the sensory organs of Drosophila melanogaster Meigen larvae (Diptera: Drosophilidae). Int. J. Insect Morphol. Embryol., 13, 255-273.

STOCKER, R. 1994. The organization of the chemosensory system in Drosophila melanogaster: a review. Cell Tissue Res., 275, 3-26.

TONOSAKI, K. AND TUCKER, D. 1982. Olfactory receptor cell responses of dog and box turtle to aliphatic $n$-acetates and aliphatic $n$-fatty acids. Behav. Neural Biol., 35, 187-199.

VENARD, R. AND PICHON, Y. 1984. Electrophysiological analysis of the peripheral response to odours in wild type and smell-deficient olf C mutant of Drosophila melanogaster. J. Insect Physiol., 30, 1-5.

WOODARD, C., HUANG, T., SUN, H., HELFAND, S. L. AND CARLSON, J. 1989. Genetic analysis of olfactory behavior in Drosophila: a new screen yields the ota mutants. Genetics, 123, 315-326. 